
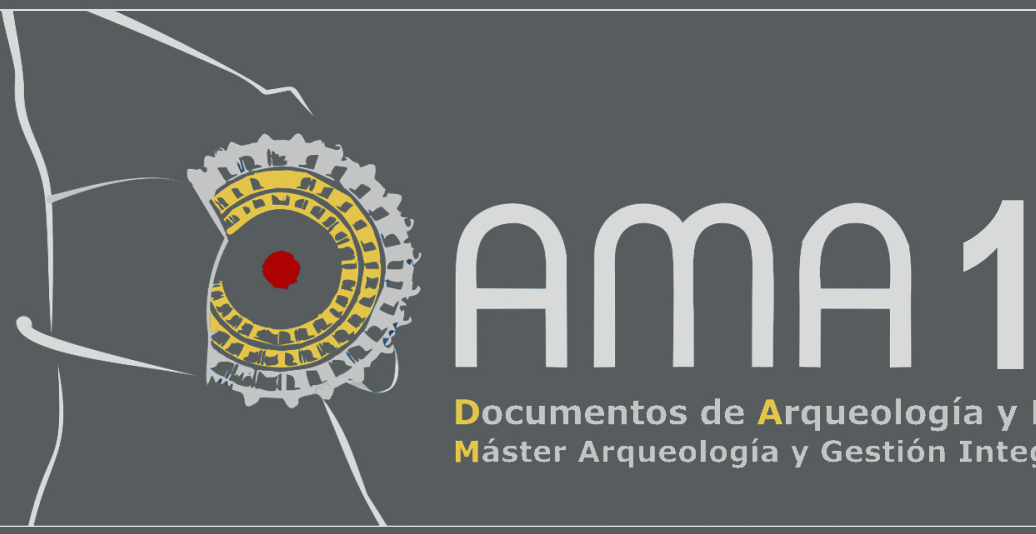

Documentos de Arqueología y Patrimonio Histórico

Máster Arqueología y Gestión Integral del Patrimonio de la Universidad de Alicante

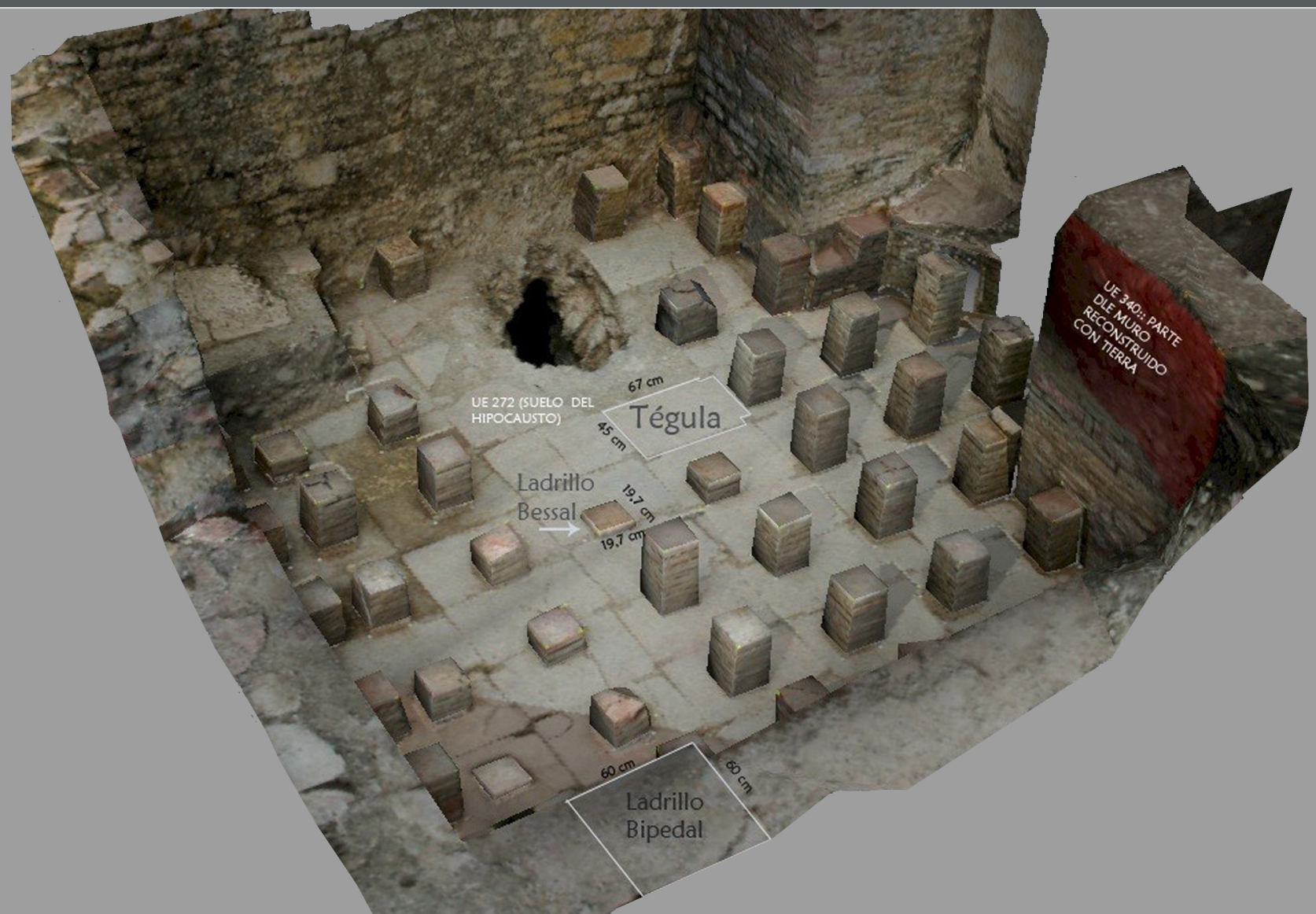

Documentos de Arqueología y Patrimonio Histórico Revista del Máster Universitario en Arqueología Profesional y Gestión integral del Patrimonio 



\section{DAMA 1}

\section{6}

DOCUMENTOS DE ARQUEOLOGÍA Y PATRIMONIO HISTÓRICO DEL MÁSTER UNIVERSITARIO EN ARQUEOLOGÍA PROFESIONAL Y GESTIÓN INTEGRAL DEL PATRIMONIO DE LA UNIVERSIDAD DE ALICANTE 


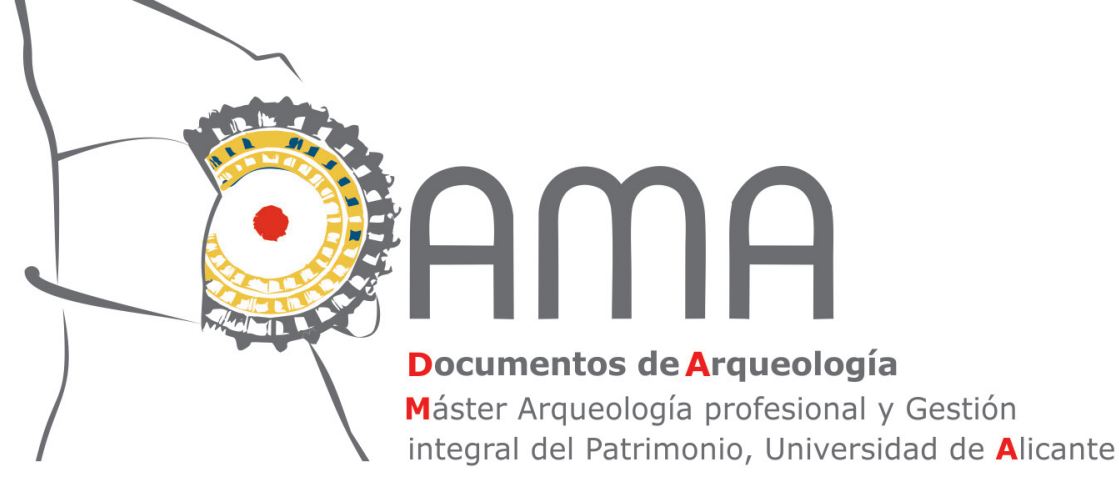

La revista electrónica DAMA. Documentos de Arqueología y Patrimonio Histórico surge como servicio para todos aquellos alumnos del Máster en Arqueología Profesional y Gestión Integral del Patrimonio de la Universidad de Alicante que se están iniciando en la investigación y cuya primera aportación a nuestra disciplina suele ser su Trabajo de Fin de Máster (TFM). Estos proyectos en muchos casos representan casi todo un curso de trabajo y esfuerzo, y con frecuencia quedan inéditos.

El objetivo de esta revista es ofrecer un medio que facilite la publicación de los resultados de sus TFM. La edición se presenta en versión digital y cuenta con su correspondiente ISSN. Se publica de forma anual en el sitio web de la Universidad de Alicante (http://web.ua.es/es/dama/) y en su repositorio (RUA). Los artículos publicados son descargables en formato PDF.

\section{Consejo de Redacción}

Directores (Coordinadores del Máster)

Carolina Doménech Belda

Fernando Prados Martínez

\section{Secretaria de Edición}

Julia Sarabia Bautista

\section{Vocales}

Los miembros de la Comisión Académica del Máster Universitario en Arqueología Profesional y Gestión del Patrimonio (http://dprha.ua.es/es/magip/comision-academica.html)

\section{Edita}

Máster Universitario en Arqueología Profesional y Gestión Integral del Patrimonio Departamento de Prehistoria, Arqueología, Historia Antigua, Filología Griega y Filología Latina

Facultad de Filosofía y Letras II

Universidad de Alicante

Ctra San Vicente del Raspeig s/n

E-03690 San Vicente del Raspeig (Alicante)

Web:http://dprha.ua.es

Teléfono: (+34) 965903663

Fax: (+34) 965903823

E-mail: revista.dama@ua.es

\section{ISSN}

$2530-2345$

\section{Portada}

Modelo fotogramétrico de un hypocaustum romano realizado por Ana Charquero 
EDITORIAL

Coordinación del máster

ENTREVISTA A SOLVEIG NORDSTRÖM: UNA MIRADA HACIA EL PASADO DE LA ESCUERA

Raúl Berenguer González ..

\section{ARQUEOLOGÍA Y MÉTODO}

EL ESTUDIO DE LOS MATERIALES CONSTRUCTIVOS DE TIERRA DEL CABEZO DEL POLOVAR (VILLENA, ALICANTE): APORTACIÓN A LAS FORMAS CONSTRUCTIVAS DE DOS PEQUEÑAS EDIFICACIONES CAMPESINAS DE LA EDAD DEL BRONCE EN EL LEVANTE PENINSULAR

María Pastor Quiles

VIVIENDAS POSTALAYÓTICAS: UNA APROXIMACIÓN A LOS ESPACIOS DOMÉSTICOS EN EL ARCHIPIÉLAGO BALEAR (550-123 ANE)

Octavio Torres Gomáriz

LAS FLOTAS DE GUARNICIÓN ROMANA EN LAS COSTAS DE HISPANIA A PARTIR DE LAS FUENTES EPIGRÁFICAS

Sergio Lledó Ramírez

UNA APROXIMACIÓN A LA RECONSTRUCCIÓN DEL PAISAJE HISTÓRICO: EL PROYECTO L'ALMISSERÀ Diana López Arroyo

NUEVAS PERSPECTIVAS PARA EL ESTUDIO ARQUEOLÓGICO DEL POBLAMIENTO RURAL MEDIEVAL EN ASPE (ALICANTE): HUERTAS Y ALQUERÍAS JUNTO AL RÍO TARAFA

Felipe Mejías López

ARQUEOLOGÍA DE LAS GUERRAS CARLISTAS

Iván Roldán Vergarachea

LA CERÁMICA DE USO ARQUITECTÓNICO EN NOVELDA: LA AZULEJERÍA DE FINALES DEL SIGLO XIX Y PRINCIPIOS DEL XX

Natalia Sala Pérez

PRÁCTICA Y USOS DE LA FOTOGRAMETRÍA DIGITAL EN ARQUEOLOGÍA

Ana $M^{a}$ Charquero Ballester.

\section{GESTIÓN Y PUESTA EN VALOR DEL PATRIMONIO}

ARQUEÓLOGOS CON DISCAPACIDAD. ARQUEOLOGÍA INCLUSIVA

Ana Samaniego Espinosa

"LES COVES DELS PESCADORS DE EL CAMPELLO": PROPUESTA DE RECUPERACIÓN, PUESTA EN VALOR Y USO PÚBLICO DE UN PATRIMONIO OLVIDADO

Ana Isabel Castro Carbonell .

LA COLONIA DE SANTA EULALIA. ESTUDIO Y PROPUESTA DE RECUPERACIÓN

Héctor de Arriba González

PROYECTO DE PUESTA EN VALOR DE LOS RESTOS DE LA GUERRA CIVIL EN LA CIUDAD DE ALICANTE

Leticia Victoria González Chouciño

ANTEPROYECTO MUSEOGRÁFICO DEL MUSEO DE HISTORIA DE SAX

Alberto Ochoa García

EL CONGRESO DE MÁSTER: UNA PROPUESTA DIDÁCTICA DEL MÁSTER DE ARQUEOLOGÍA DE LA UNIVERSIDAD DE ALICANTE

Ignasi Grau Mira, Sonia Gutiérrez Lloret, Carolina Doménech Belda, Julia Sarabia Bautista 



\title{
LA COLONIA DE SANTA EULALIA. ESTUDIO Y PROPUESTA DE RECUPERACIÓN
}

\author{
Héctor de Arriba González
}

\section{RESUMEN}

La colonia de Santa Eulalia es una colonia agrícola fundada a finales del siglo XIX en base a la ley de 11 de junio de 1868. Este enclave rural se encuentra hoy abandonado y en estado ruinoso. A través de este artículo presentamos el plan de recuperación como espacio museístico planteado en el año 2012 como Trabajo de Fin de Máster.

Palabras claves: Colonia agrícola, Santa Eulalia, musealización, Vinalopó, patrimonio industrial, comunicación.

\section{ABSTRACT}

Santa Eulalia's colony is an agricultural community founded in last years of XIX century. Nowadays, this village is abandoned and tumbledown. In this paper we present the results of Master's degree's dissertation: a recuperation project as museum of Santa Eulalia's colony.

Key words: Agricultural community, Santa Eulalia, museum, Vinalopó, industrial heritage, cultural communication. 


\section{INTRODUCCIÓN}

La Colonia de Santa Eulalia es un enclave agrícola e industrial singular situado en el límite entre los términos municipales de Villena y Sax en la provincia de Alicante. Su fundación en 1886 responde a una serie de factores legales y económicos que propician esta empresa agro-industrial y que permiten su funcionamiento durante cuatro décadas. Sin embargo, una vez que cesa su actividad económica se inicia un progresivo declive que llega hasta la actualidad con unos edificios aún reconocibles, pero en estado ruinoso.

La singularidad de este enclave histórico y su valor como ejemplo de los cambios de una de las etapas más interesantes de la historia reciente de España convierten esta colonia agrícola en un espacio de gran interés cultural. Ese fue el principal motivo por el cual, durante la promoción del año 2011-2012 del Máster universitario en Arqueología profesional y gestión integral del Patrimonio de la Universidad de Alicante, propusimos la realización de una propuesta de recuperación de la Colonia de Santa Eulalia como espacio museístico. Dicho trabajo fue realizado bajo la tutoría de la profesora Dra. Carolina Doménech Belda.

La propuesta de musealización presentada a través de este Trabajo de Fin de Máster (TFM) tenía también como objetivo proponer un nuevo elemento de oferta turística dentro de la provincia de Alicante. De esta manera, un museo sobre la Colonia de Santa Eulalia serviría de complemento al turismo tradicional de sol y playa de la provincia. También sería una propuesta que se integraría perfectamente dentro de los programas de promoción turística de la Ruta de los castillos y la Ruta del Vino a su paso por la cuenca del río Vinalopó.

El presente artículo respeta la estructuración del TFM y se divide en dos partes diferentes pero relacionadas: primeramente, se presentarán algunos elementos de la historia de las colonias agrícolas en general y de la colonia de Santa Eulalia en particular para, a continuación, señalar algunos de los aspectos más destacados de la propuesta de musealización realizada a través del trabajo.

\section{COLONIAS AGRÍCOLAS EN ESPAÑA}

Definir una colonia agrícola es un proceso que resulta más complejo de lo que podría parecer. Es un concepto que responde a numerosas representaciones y posibilidades sobre el terreno (Canales, 1998, pp.346-361). Con el fin de poder abarcar el máximo posible de ejemplos de colonias peninsulares durante el siglo XIX y XX, durante la realización del TFM propusimos como definición: "una iniciativa de carácter público o privado en el entorno rural y distanciado de los núcleos de población para, en virtud de la legislación vigente, poner en cultivo nuevas tierras con población foránea, mejorar las explotaciones tanto nuevas como ya iniciadas $y$, en algunos casos, transformar industrialmente la producción" (De Arriba, 2012, p. 32).

La colonia de Santa Eulalia fue creada bajo el amparo de la ley de 3 de junio de 1868. Dicha ley se desarrolla como una reforma de la ley de 21 de enero de 1855, que tenía igualmente el objetivo de potenciar el desarrollo de nuevas zonas de cultivo y el asentamiento de población rural (Paniagua, 1990: 824). Sin embargo, resultó infructuosa y solo 6 solicitudes fueron aprobadas de las 33 que se presentaron (Paniagua, 1990, p. 828).

Por ese motivo se lleva a cabo la creación de una nueva legislación en 1866, introduciendo una serie de novedades importantes que serán la base de la ley definitiva creada dos años después. La ley de colonias agrícolas de 1868 suponía el compendio de todas las leyes anteriores y añadía a ellas nuevas disposiciones para favorecer las iniciativas privadas de tipo agroindustrial (Abellá. 1877, pp. 319-320): exenciones de diversos impuestos, beneficios fiscales por la roturación de terrenos con 
ciertos cultivos, permitir a los quintos pasar a la reserva y, en el caso de las colonias de más de 100 habitantes, el mantenimiento de servicios médicos, educativos y religiosos por parte del Estado.

Su éxito fue mucho mayor que el de las legislaciones precedentes, aunque el número de solicitudes fue limitado hasta el comienzo del reinado de Alfonso XII. Sólo en el año 1875 se producen cerca de 800 solicitudes en toda España, cantidad que se estabiliza por encima de las 50 solicitudes por año hasta 1886 (Paniagua, 1990, pp. 829-830). En muchos casos se trataba de un medio de obtener prestigio por parte de sus propietarios, pues pocas empresas continuaron más allá de dos años (Canales, 1990, p. 358), pero aquellas que realmente tenían un objetivo de rentabilidad económica funcionaron como ejemplos de innovación tecnológica (Oyón, 1985, pp. 26-27).

\section{LA COLONIA DE SANTA EULALIA}

La fundación de la colonia es llevada a cabo por D. Antonio de Padua Saavedra y Rodríguez de Guerra, IX Conde de la Alcudia y XII conde de Gestalgar (Vázquez, 2010, p. 35) a comienzos de 1886 (Jaén et al., 2000, p. 421). Con ello busca poner en cultivo los terrenos de los "prados de Santa Eulalia" aprovechando los beneficios legales y tributarios para las promociones de colonias agrícolas de la ley de 1868.

Los terrenos donde se sitúa pertenecían a la familia del conde desde mediados del siglo XIX. En el momento de la fundación, el único edificio importante que existía en ellos era la ermita de santa Eulalia (Fig. 1). Además, su estado de conservación hizo necesaria una reforma o reconstrucción, atestiguada por una placa que se conserva dentro de la misma.

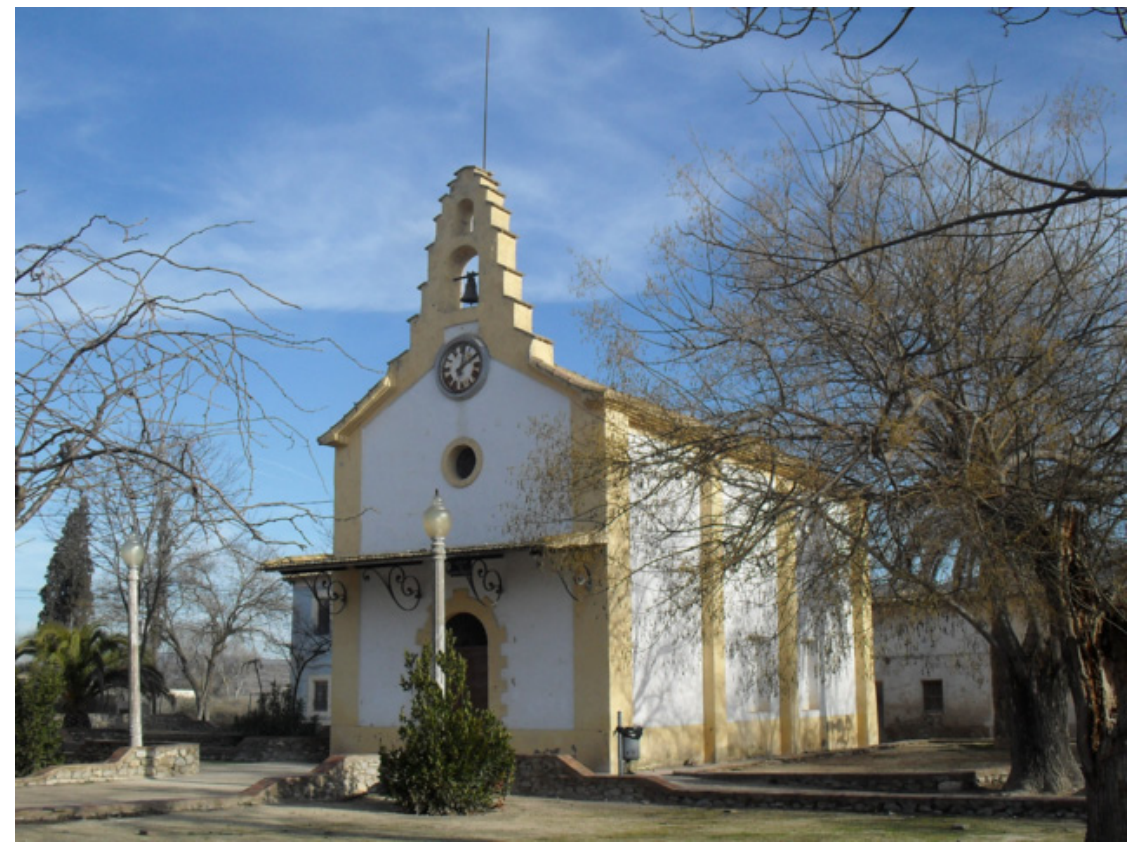

Fig. 1. Vista general de la actual ermita de Santa Eulalia
Entre 1886 y 1900 lacolonia tiene una vocación puramente agrícola y se encuentra bajo la dirección del conde en solitario con la vocación de convertirse en un enclave autosuficiente (Vázquez, 2010: 36). En este periodo se construyen la casa-palacio, las viviendas de obreros, las estructuras de almacenamiento y algunos espacios de transformación de la producción. Gracias a su iniciativa se lleva a cabo la instalación de una línea telefónica en 1890, de una rueda hidráulica en 1896 (Jaén et al., 2000, p. 422) y una oficina de Correos.

Será a partir de los primeros años del siglo XX cuando la colonia adquirirá su carácter industrial. El conde se asocia con D. Mariano de Bertolano y Roncalí, Vizconde de Alcira e ingeniero agrónomo y su esposa, Da . María de la Concepción Avidal Peña, la cual aporta el capital suficiente para crear las nuevas estructuras que dan a la colonia su aspecto actual (Vázquez, 2008, p. 32). Según un informe pericial de 1907 realizado por el Ayuntamiento de Sax (Archivo de Sax, caja 904, doc. 30) se construyen en esos años nuevos molinos de aceite, la alcoholera, las bodegas y la fábrica de harinas entre otros edificios y se lleva a cabo una transformación de la base productiva con nuevas plantaciones de vides, olivos y almendros. 
La estructura de la colonia de Santa Eulalia presenta una planta organizada en torno a dos plazas de planta cuadrangular (Fig. 2). Esto era algo defendido por los principales manuales europeos como base para el diseño de estos espacios agrícolas (Oyón, 1985, p. 38-39). Con ello se buscaba el control del campesinado, la reducción de los tiempos de desplazamiento hacia los campos y la concentración de las actividades (Oyón, 1985, p. 39-40). Una vez en el siglo $\mathrm{XX}$, este ideal de vigilancia irá decayendo y siendo sustituido por una tendencia a la mejora de las condiciones de vida de la población de las colonias. Mediante la mejora de la vivienda, la educación y los espacios de ocio se pretendía evitar el desarrollo de posicionamientos políticos radicales entre el campesinado (Baeza, 2009, p. 103).

El 23 de mayo de 1907 concluyen los beneficios legales y tributarios de los que disfrutaba la colonia de Santa Eulalia. Desde ese momento hasta la finalización de la empresa en 1930, la colonia sigue funcionando a pesar de diversos problemas personales entre los dueños de la empresa, el aumento de las cargas tributarias y la crisis del sector vitivinícola español. En

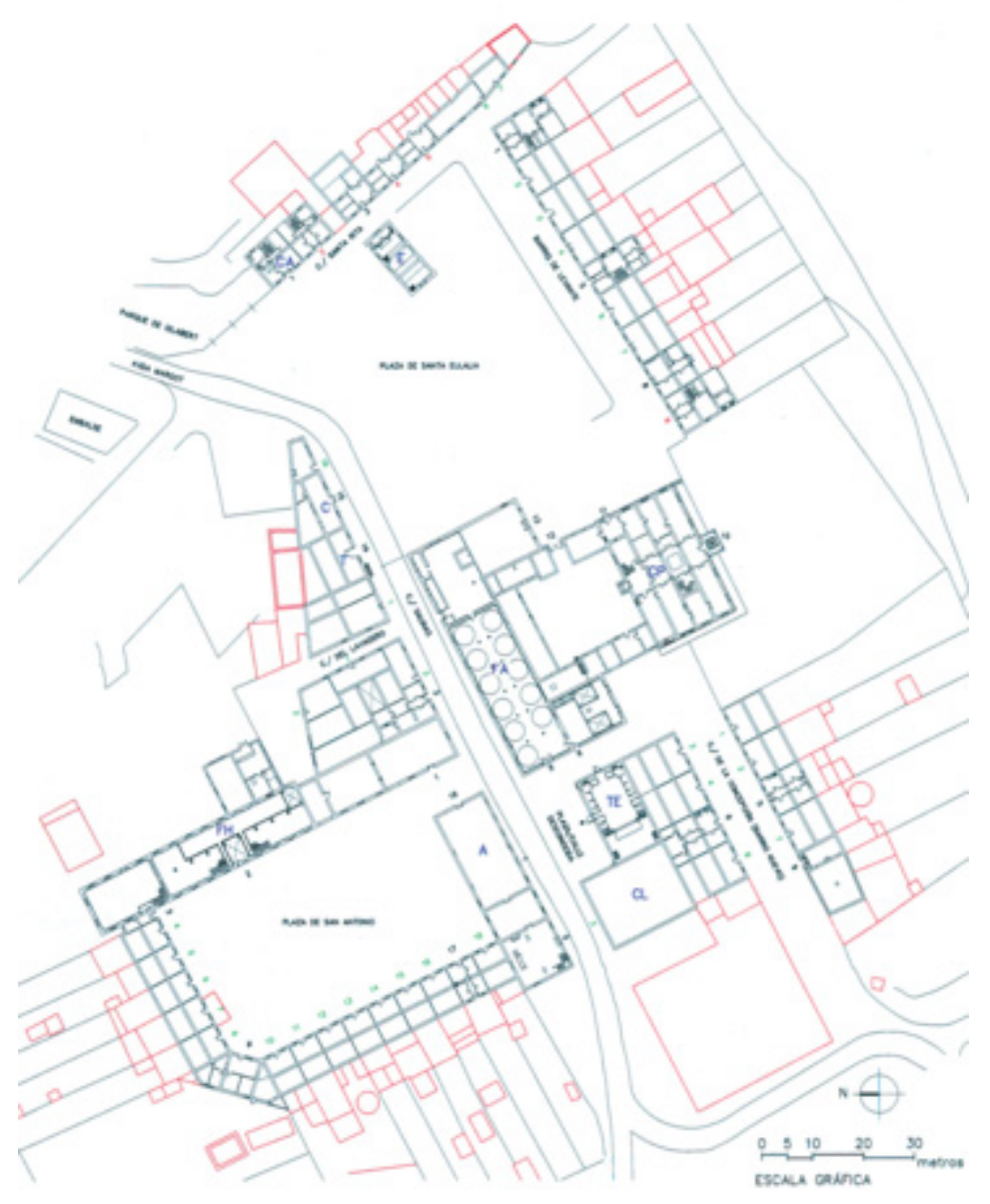

Fig. 2: Plano de la colonia de Santa Eulalia elaborado por Jaén y otros (2000) 1910 D. Mariano de Bertolano abandona el proyecto de la colonia y su esposa pasa a ser la propietaria. En 1925 fallece el conde de la Alcudia y unos años después del final de la Guerra Civil española se produce el cese final de la actividad. La diversificación de la producción y una ligera recuperación durante los años de la Primera Guerra Mundial explican que, a pesar del contexto económico adverso, la colonia pudiera seguir funcionando durante veintitrés años después de terminarse los beneficios ligados a su estatus.

En la actualidad la colonia se encuentra en estado de casi total abandono. Algunas de las viviendas continúan ocupadas, bien de forma permanente o como segunda vivienda, pero los principales edificios industriales, el teatro y la casa-palacio están en un estado cercano a la ruina y a merced de los elementos. Durante la última década se han presentado algunas propuestas de recuperación sin que ninguna llegase a ver la luz. En el año 2016 la colonia ha recibido por parte de la Consejería de Cultura la protección de Bien de Interés Cultural, en la categoría de Espacio Etnológico.

\section{PROPUESTA DE RECUPERACIÓN}

A partir del estudio realizado sobre la historia de colonia de Santa Eulalia y el análisis de los edificios conservados, la primera conclusión que extraemos es el gran potencial de este enclave. A través de este espacio patrimonial podría llevarse a cabo una divulgación del pasado reciente de las comarcas del Vinalopó y de la provincia de Alicante. Sin embargo, antes de aventurarnos a plantear posibles 
propuestas decidimos realizar un estudio de viabilidad con el fin de conocer los puntos fuertes y débiles del proyecto.

\section{ANÁLISIS DAFO/CAME}

Las herramientas que nos han ayudado a realizar tal estudio fueron los análisis DAFO y CAME. En el TFM señalamos que ambas herramientas han de ser trabajos multidisciplinares y que, por tanto, nuestros resultados no son más que una aproximación. De todos modos, tales análisis nos permiten conocer algunas de las ventajas de la colonia como espacio museístico y las desventajas a superar.

El análisis DAFO (SWOT en inglés) permite una evaluación de factores positivos y negativos del proyecto (Hervás, 2006, p. 25): Debilidades, Amenazas, Fortalezas y Oportunidades. Estos resultados nos permiten obtener una idea clara de los elementos que favorecen o ponen en riesgo el proyecto. A partir de ellos han de desarrollarse una serie de estrategias que nos permitan hacer frente a los riesgos y multiplicar los puntos fuertes. Dichas estrategias pueden ser obtenidas a través de una segunda herramienta: el análisis CAME (Corregir, Afrontar, Mantener y Explotar). Combinando los cuatro resultados DAFO se obtienen una serie de líneas maestras de actuación a fin de maximizar las fortalezas-oportunidades y minimizar las amenazas-debilidades.

Si bien no vamos a incluir en este artículo los resultados detallados del análisis, cabe señalar algunas de las conclusiones que obtuvimos. Las estrategias a seguir pasan por aprovechar el turismo tradicional de la provincia como fuente principal de visitantes, establecer contactos con las entidades locales y comarcales próximas para crear programas educativos y de divulgación y reforzar la colaboración ciudadana a través de actividades culturales de interés. En sentido contrario, algunos de los factores que dificultarían el desarrollo del proyecto son la escasez de financiación, la necesidad de realizar importantes trabajos de restauración sobre la mayoría de los edificios, el desconocimiento de la titularidad de muchos de ellos y la situación administrativa de la colonia, emplazada en el límite de dos términos municipales.

\section{UN MUSEO DE SITIO}

Como ya señalamos anteriormente, varias propuestas de recuperación de la colonia se han planteado durante la última década. Sin embargo, ninguna de ellas ha llegado a realizarse. Su protección como Bien de Interés Cultural es un primer paso muy importante que nosotros reclamábamos en el TFM. Pero no se debe pensar que con eso es suficiente. La protección jurídica no evitará que el paso del tiempo siga degradando los edificios. La única solución durable es el desarrollo de un plan de recuperación integral que incluya la restauración de los edificios y un aprovechamiento útil para la sociedad. Nuestra propuesta en este sentido ha sido la transformación de la colonia de Santa Eulalia en un museo de sitio donde se puedan dar a conocer la historia del enclave y su contexto histórico. Por "museo de sitio" entendemos "una exposición monográfica permanente sobre un yacimiento arqueológico, monumento o lugar histórico, situada en sus inmediaciones o en su interior" (Espinosa, 2004, p. 8).

Al contrario que en muchos museos de arte o de arqueología, en la colonia contamos con la posibilidad de mostrar tanto los bienes muebles como los inmuebles y espacios donde la historia tuvo lugar. Contamos con un enclave que ha sufrido pocas alteraciones desde el abandono de su función original en la década de los años 30 y que representa muchos de los aspectos de la vida a principios del siglo XX:

Las viviendas de trabajadores y la casa-palacio muestran las condiciones de alojamiento y la vida cotidiana de las familias obreras y burguesas respectivamente. 
Las instalaciones industriales permiten explicar la importancia del vino y el aceite en la economía del Vinalopó, así como las nuevas técnicas de producción industrial relacionadas con la agricultura.

La estación de ferrocarriles nos permite mostrar la importancia de la línea de Madrid-Alicante para la economía de la colonia y de la provincia.

Los edificios de servicios como el casinete, la hospedería o la oficina de Correos sirven para introducir la explicación sobre las dificultades de comunicación y transporte.

La iglesia, el patio y el teatro muestran el papel central de la religión, las festividades y la vida cultural en la colonia.

Estas son sólo algunas posibilidades de comunicación que presentan los edificios de la colonia de Santa Eulalia. Por esos motivos, nuestra propuesta gira en torno a una recuperación integral de los diferentes espacios del enclave rural junto con los objetos propios de la época. El diseño museológico ha de centrarse en la experiencia global del visitante más que en una serie de piezas y documentos aislados (Calaf, 2003, p. 52). Si se consigue la inmersión del público en las condiciones de vida a principios del siglo XX, la comprensión del mensaje del museo resultará más sencilla.

Uno de nuestros modelos a la hora de realizar esta propuesta ha sido el Consorci del Parc Fluvial del Llobregat, una red de 18 colonias creadas siguiendo el curso de dicho río y que han sido recuperadas y musealizadas. Cada una de ellas se encuentra especializada en un aspecto de su historia. Por ejemplo, en la colonia de Cal Pons se explica la importancia del papel de la Iglesia, en la Torre de l'Amo de Viladomiu Nou el visitante puede conocer quienes era los empresarios que crearon estas colonias y en Cal Vidal la exposición está centrada en la vida de los trabajadores y el sistema de producción industrial. En su conjunto forman una visita completa que permite al visitante sumergirse en el contexto social de la época y prolongar su estancia en la comarca durante varios días.

En la colonia de Santa Eulalia contamos con capacidad para mostrar todos esos aspectos, aunque no todos podrían ser explicados a la vez. En ese caso la visita sería demasiado larga o con tantos aspectos diferentes que dificultaría una exposición clara. La oferta debe ser variada (Valdés, 1999, p. 78) pero hemos de evitar que el visitante se canse y desvíe su atención. Por ese motivo es necesaria una selección de una serie de ideas clave que todo visitante mínimamente interesado pueda retener una vez haya terminado su estancia en el museo. Esos conceptos serán la base de las exposiciones y visitas. A ello se añadirá la posibilidad de profundizar en otros aspectos a través de partes de las visitas opcionales, exposiciones temporales u otras actividades puntuales.

El museo, como cualquier otro espacio cultural, ha de ser un entorno de comunicación entre la ciencia y el visitante, un espacio educativo y un foco de desarrollo cultural y científico. No se debe tampoco olvidar que se trata de un lugar turístico al que los visitantes acuden, por norma general, por propio interés y en el que han de divertirse mientras se les ofrece una información. Por todo ello, es tan importante conocer quiénes serán los visitantes del museo como la organización de las visitas y la elaboración de medios didácticos y de comunicación adecuados.

\section{ORGANIZACIÓN DE LAS VISITAS}

A la hora de diseñar cómo será el aprovechamiento del espacio museístico, han de tenerse en cuenta numerosos aspectos tales como las características físicas de las instalaciones, el discurso que se pretende desarrollar, el tiempo medio de visita, etc. A grandes rasgos podemos dividir los tipos de museos entre los que la visita libre del visitante es la fórmula más habitual, aquellos que por sus características priorizan la visita guiada y los que ofrecen fórmulas mixtas con una parte de visita libre y otra guiada. 
En la colonia de Santa Eulalia las características del enclave presentan una serie de condicionantes específicos. Por un lado, la entrada a la colonia no puede ser limitada, pues se trata de un espacio público. Los espacios al aire libre y los exteriores de los edificios pueden ser visitados sin ninguna limitación y sin que sea exigido el pago de entrada. Es el acceso al interior de los edificios, las visitas comentadas por parte de los guías y la asistencia a diversos eventos lo que puede ser susceptible del pago de un derecho de acceso. Tampoco es recomendable el empleo de numerosos paneles explicativos fijos que permitan al visitante realizar una visita completa de manera autónoma. De ese modo sólo se consigue dificultar el desplazamiento y modificar la percepción de los espacios. Sin contar con el hecho de que no todos los visitantes están interesados en la lectura de la información escrita en esos carteles.

En vista de estas limitaciones, nuestra propuesta de musealización se organiza de la siguiente forma:

Visita a los espacios abiertos de la colonia sin ningún impedimento. No es posible obligar al visitante a pagar una entrada para acceder a un espacio público como las calles de la colonia, lo cual supone la mayor parte de los espacios abiertos.

\begin{tabular}{lr}
\multicolumn{1}{c}{ En los espacios } \\
exteriores más \\
representativos r \\
importantes de la colonia \\
se emplazarán algunos \\
carteles explicativos e \\
indicativos, buscando
\end{tabular}
con su forma, tamaño o color que sean fácilmente

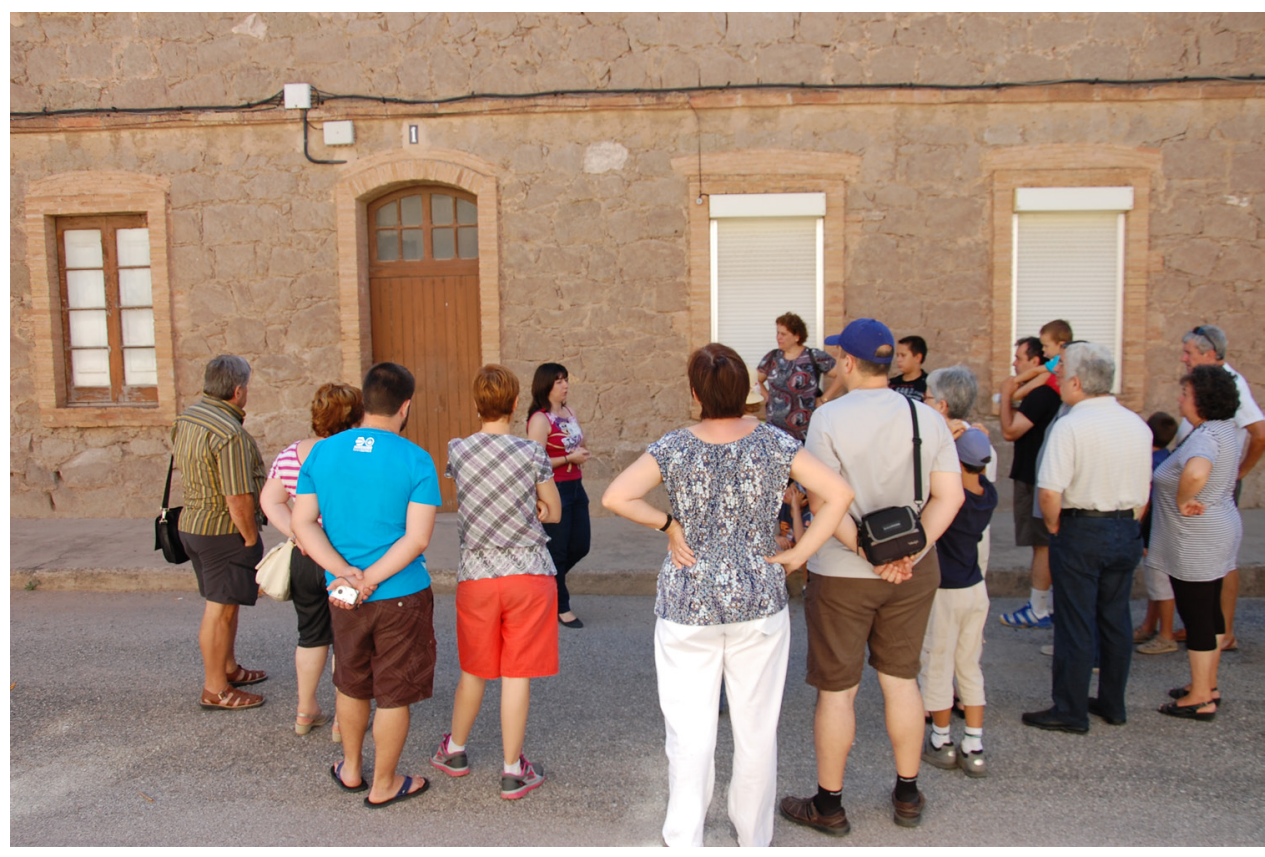

Fig. 3. Visita guiada a la colonia Cal Vidal (Barcelona) identificables, pero no

alteren en exceso el conjunto del enclave. Dichos carteles sustituirán a los existentes, siguiendo criterios museográficos más modernos y empleando materiales que equilibren el coste con su durabilidad al aire libre. Estos deben permitir a los visitantes obtener la información básica para comprender los aspectos esenciales de la colonia.

Junto a la visita libre que el propio visitante puede realizar, el museo ofertará la posibilidad de realizar visitas guiadas a los espacios interiores de algunos edificios (Fig. 3). De esta manera se transmitirá una información más detallada que la disponible en los carteles y permitirá una comprensión más completa de las condiciones de vida dentro de la colonia de Santa Eulalia. La reconstitución de los espacios interiores resultará, en ese sentido, esencial para facilitar al visitante una inmersión completa en la narración.

La recepción de los visitantes, el punto de información y otros servicios básicos de la colonia se realizarán en un edificio especialmente habilitado para ello. Puesto que este ha de ser el punto de inicio de las visitas, en este espacio puede realizarse una pequeña exposición permanente que sirva de introducción y contexto histórico general. Mediante paneles, fotografías y algunos 


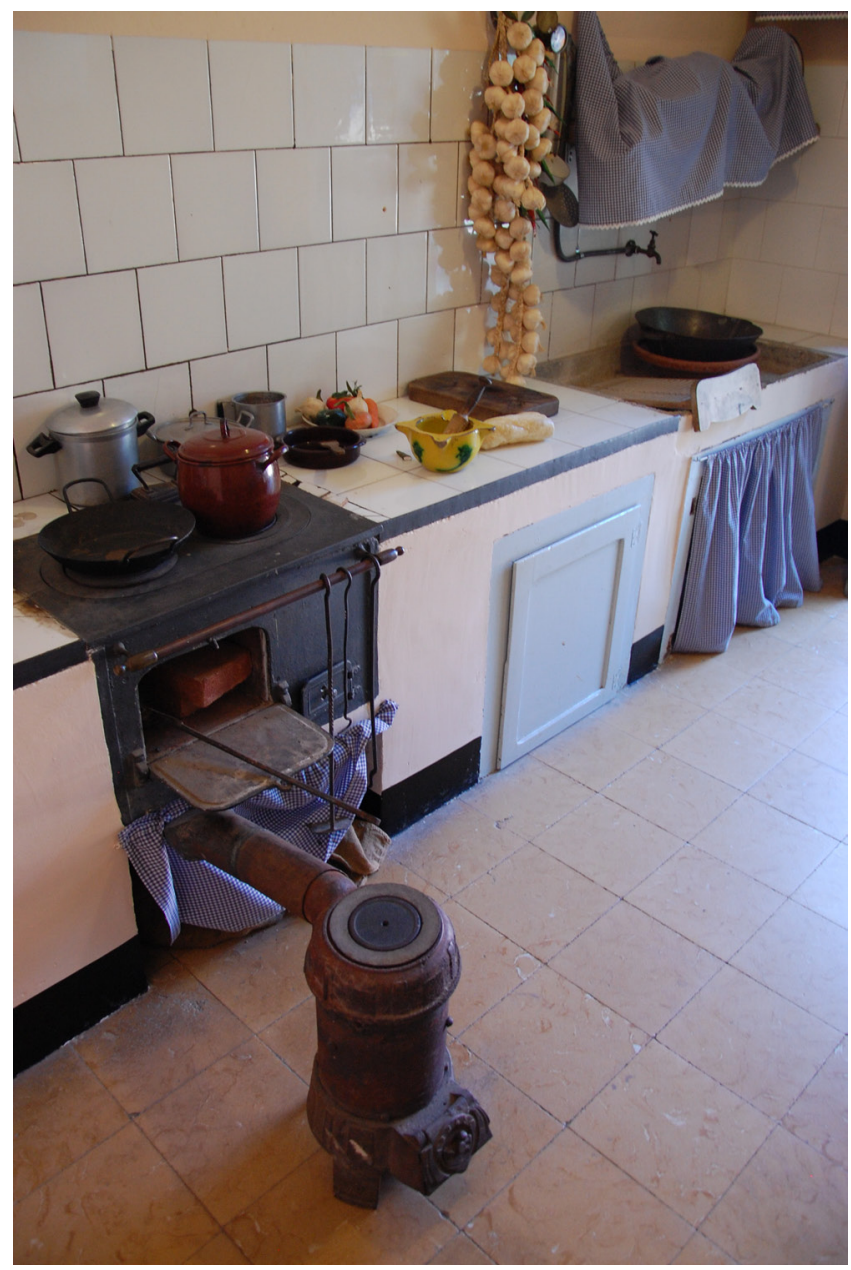

Fig. 4. Recreación de una de las cocinas en el Museo de las Minas de Cercs (Barcelona) objetos representativos, el visitante podrá, individualmente o a través de la mediación de un guía, obtener una visión de conjunto de qué es la colonia y cuál es su importancia histórica.

Determinados espacios, estén o no cerrados al público de forma habitual, podrán habilitarse para la realización de exposiciones temporales y la celebración de cursos, ciclos de conferencias, actuaciones y otros eventos. Estas actividades podrán ser organizadas por el propio museo o por instituciones culturales y asociaciones que soliciten su uso.

El museo puede disponer de un espacio destinado a la realización de talleres didácticos, lo cual permite reforzar algunos de los conceptos explicados dentro de las visitas de grupos. Esto es especialmente interesante en el caso de grupos escolares.

Este proyecto de musealización otorga una gran importancia a la percepción y la experiencia del visitante en el interior de los espacios. El objetivo a alcanzar es que, durante la visita, cada uno se pueda imaginar cómo era la vida a finales del siglo XIX y principios del XX a través del contacto directo con las condiciones en que vivieron los habitantes de la colonia. Por ese motivo, una parte importante del proyecto lo ocupan el mobiliario, la decoración y los utensilios históricos que nos permitan reproducir esas condiciones de vida y que los visitantes podrán ver e incluso tocar (Fig. 4).

En este tipo de escenificaciones museográficas el objetivo es la fidelidad respecto a la situación real en la época correspondiente. Para ello se intentará disponer el mayor número posible de objetos que fueron fabricados y utilizados por personas en situaciones reales, es decir, objetos históricos. No obstante, a medida que retrocedemos en el tiempo, la cantidad de ellos que siguen estando a la venta o conservados en otros museos es más limitado. Más incluso si nos referimos a objetos de la vida cotidiana como vajillas, ropa, juguetes etc. Con el fin de paliar esta deficiencia, la práctica museística permite el empleo de reproducciones que imiten de manera fiel y generen un sentimiento de autenticidad. Esta ha de ser una solución empleada tanto para sustituir aquellos objetos de los que ya no disponemos y, al mismo tiempo, permitir el contacto por parte de los visitantes. El empleo de reproducciones es una práctica que el Reglamento que regula la actividad de los museos permite con el fin de "facilitar la investigación y la difusión cultural". Además, al disponer de numerosos testimonios y documentos gráficos de la vida a principios de siglo es posible el empleo de reproducciones sin producir "falsos históricos".

Con el fin de trasmitir al visitante cómo era la vida cotidiana y la producción agro-industrial en la colonia, los espacios propuestos para las visitas guiadas son: una vivienda de trabajadores, la casapalacio, la ermita, la fábrica de alcoholes, la bodega, el lagar y el teatro. El resto de edificios pueden ser explicados sin necesidad de acceder al interior o, visitarlos dentro de rutas con objetivos específicos, 
como en el caso de grupos escolares o eventos puntuales. De esta manera se obtiene un recorrido con una duración aproximada de una hora o una hora y media por los edificios más representativos del enclave.

Paralelamente, algunos de los espacios pueden servir también para la realización de talleres, conferencias y otros eventos organizados por el museo, sus patrocinadores o las asociaciones locales. De este modo se permite dinamizar las actividades propuestas a la vez que se potencia una red de colaboración cultural entre los distintos actores de la provincia.

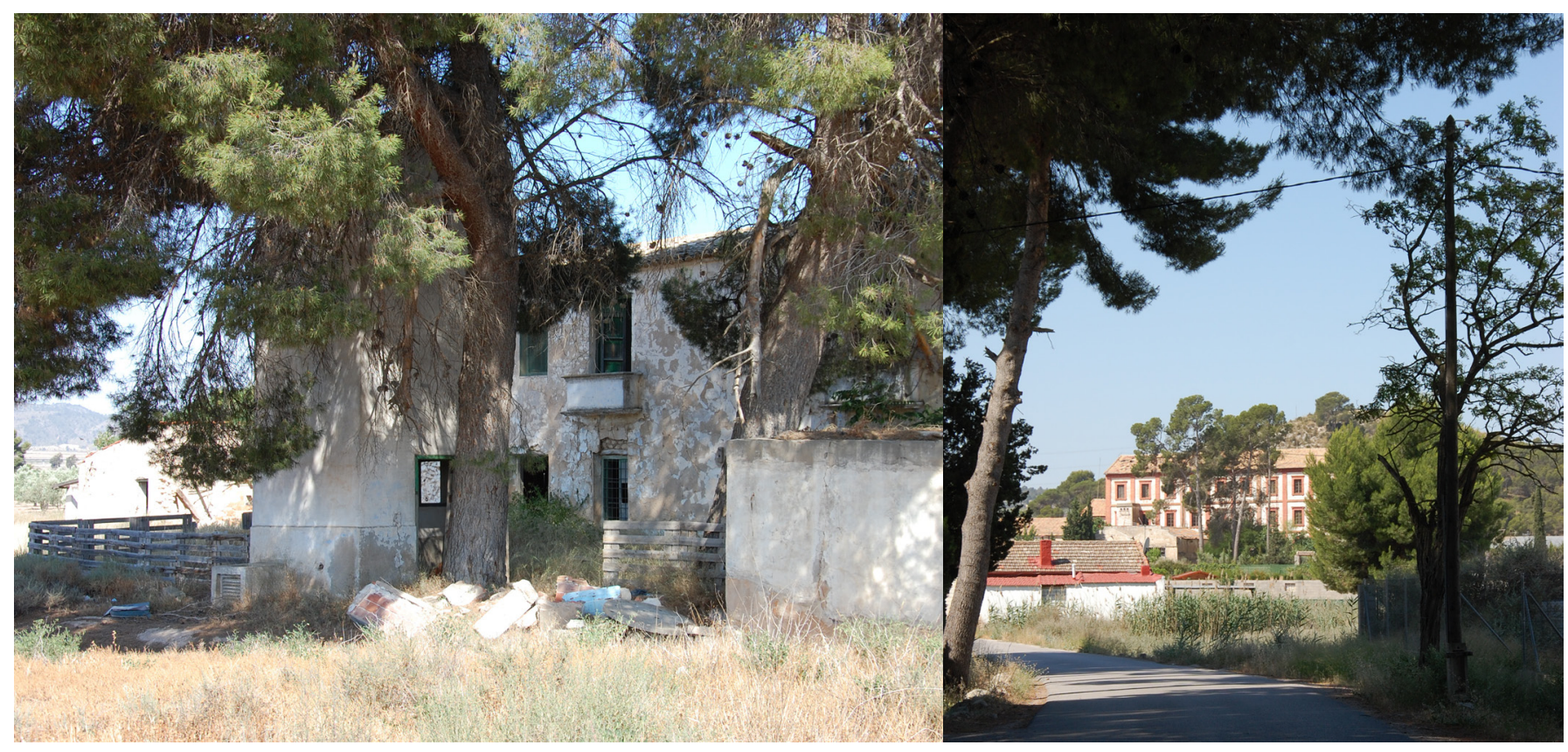

Fig. 5 y 6. Edificio abandonado junto a la estación de tren de la colonia y camino que une el centro de recepción de visitantes y la colonia

Por último, se plantea un aspecto importante: la ubicación del espacio de recepción de visitantes. Nuestra propuesta en el momento de realización del TFM fue un terreno junto a una antigua vivienda que se sitúa próxima a los restos de la estación de ferrocarriles de la provincia. (Fig. 5). El edificio se encuentra abandonado y, por tanto, su recuperación requiere una restauración y adaptación a las necesidades de su nueva función como espacio de recepción de visitantes. Nuestra elección responde al hecho de que se encuentra al exterior del núcleo principal de la colonia, pero directamente conectado a través de una pequeña carretera (Fig. 6). Ese recorrido de unos 10 minutos a pie hará las veces de un "túnel del tiempo" a través del cual los visitantes pueden adaptar su percepción hacia la idea de entrar en un espacio del siglo XIX de manera progresiva. Dispone también de terrenos a su alrededor en los que se podrían disponer espacios de aparcamiento de vehículos, de una gasolinera junto a la Casa del Cuco y acceso directo desde la autovía A-31.

\section{CANALES DE COMUNICACIÓN}

Un museo ha de ser un foco de desarrollo cultural y científico, formar parte de la oferta turística de su región y ser un generador de externalidades positivas hacia las empresas y espacios próximos. Pero la gestión de un museo también debe ser analizada como un medio de comunicación de masas y un espacio educativo en el que se transmite un mensaje relacionado con el patrimonio en él conservado. Esa es la función principal de todo museo y por ello muchas de las leyes de patrimonio en España incluyen la difusión como una de las funciones básicas de todo museo (Valdés, 1999, pp. 45-50). 
Los encargados de la difusión en el museo tienen una doble función: por un lado, son los encargados de sociabilizar el conocimiento relativo a sus fondos patrimoniales y, por otro lado, tienen que colaborar a la "educación informal" de sus visitantes en aspectos como la importancia del patrimonio, cómo y por qué éste debe ser conservado, el trabajo de los científicos, etc. Los aspectos comunicacionales de todo museo deben ser analizados y planificados detalladamente. Los museos que más éxito tienen y más visitantes atraen son aquellos que mejor realizan su labor de comunicación, con excepción de los grandes museos como el Prado, el Reina Sofía o el Louvre que exponen numerosas obras maestras y son la visita obligada para todo turista. Todo esto se realiza, como veremos a continuación aplicado a la colonia de Santa Eulalia, a través de exposiciones, actividades didácticas, publicaciones, jornadas de estudio, etc.

\subsection{Canales horizontales, métodos de difusión no selectivos}

Para los visitantes ocasionales de un museo, la imagen estereotipada del mismo es una sala donde hay objetos en vitrinas u obras de arte junto con carteles que explican lo que es cada cosa. Todo ello conforma los canales horizontales de la comunicación de un museo. Se trata de la materia prima de la exposición, pensada para ser comprendida por un público medianamente interesado y que dedica una parte de su tiempo de visita a la lectura de la información.

El principal medio de comunicación del museo es la exposición de los bienes patrimoniales que conserva (Valdés 1999, p. 195). Las colecciones permanentes presentadas al público tienen una larga duración con pocas variaciones en su forma y contenido. En el caso de la colonia de Santa Eulalia, los bienes que han de emplearse para la exposición permanente es todo el enclave en su conjunto. Es decir, los edificios restaurados y determinados espacios interiores que serán recuperados para reproducir las condiciones de vida de principios del siglo XIX (Fig.7).

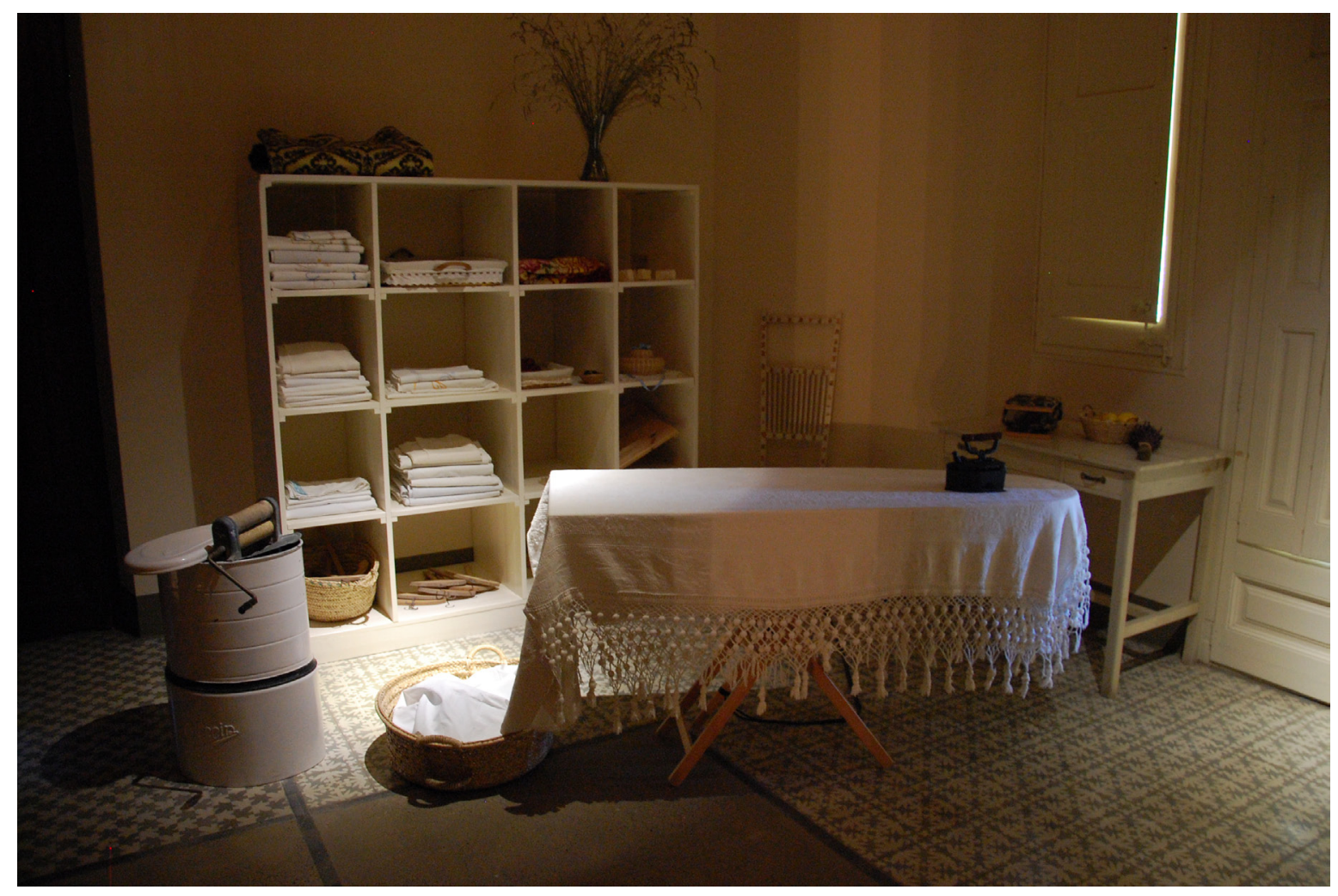

Fig. 7. Recreación de una sala de costura en la colonia de Viladomiu Nou (Barcelona) 
Uno de los principales atractivos para el público son las exposiciones temporales. Suponen uno de los principales recursos de publicidad pues permiten dinamizar la oferta cultural del museo, complementando a la exposición permanente o tratando en mayor detalle alguno de sus aspectos. También ponen en relación objetos que normalmente se encuentran dispersos en diferentes instituciones y colecciones privadas. La organización de este tipo de exposiciones requiere un trabajo de investigación y gestión que comienza varios años antes de la inauguración de la exposición y permite a los técnicos experimentar con nuevos recursos y criterios museográficos (Valdés, 1999, p. 194; Belcher, 1997, p. 64). En el caso de pequeños museos donde las posibilidades de organización de exposiciones temporales son más limitados, existe la posibilidad de contratar exposiciones itinerantes. Éstas son exposiciones temporales que han sido realizadas por grandes museos y que, una vez finalizadas, son alquiladas a otros más pequeños con el fin de rentabilizar la inversión realizada (Belcher, 1997, p. 66). Las posibles temáticas para las exposiciones en la colonia de Santa Eulalia son muy amplias. A través de ellas se puede profundizar en algún aspecto en concreto de la misma que no siempre es explicado durante las visitas guiadas. Algunos posibles ejemplos son la historia de los cultivos presentes en la colonia, la vida de sus habitantes, las técnicas de producción industrial empleadas, etc.

El elemento más importante de la comunicación horizontal de todo museo son los carteles explicativos que proporcionarán al visitante las herramientas para la comprensión de las exposiciones. Si bien no vamos a profundizar aquí en todas las características técnicas de la propuesta realizada para la colonia de Santa Eulalia, pues se pueden encontrar en el propio TFM y en la literatura especializada (Hooper-Greenhill, 1988, pp. 157-188; Espinosa y Bonmatí, 2012), si indicaremos algunas de ellas. Los carteles deben responder a criterios de divulgación en cuanto a la facilidad de lectura, concisión y presentación de unos pocos aspectos clave. Los textos deben estar escritos en una tipografía clara, de 1 centímetro de altura, en color negro con fondo blanco, no contar con más de 80 palabras como máximo y alineadas a la izquierda. También puede emplearse diferentes colores en los bordes de los carteles o de sus soportes para diferentes categorías o temáticas del contenido. Los materiales empleados deben der ser resistentes, no muy caros y fácilmente sustituibles. Esto es especialmente importante por el hecho de que los carteles en la colonia se encontrarán en espacios exteriores, expuestos a la climatología o la posibilidad de actos vandálicos. Por ello los materiales propuestos son: una estructura básica de acero inoxidable que se eleve a una altura de 100 o 110 centímetros para permitir una lectura cómoda tanto de pie como desde una silla de ruedas (Espinosa y Bonmatí, 2012, p. 11). Sobre ella se instalará el panel, impreso en papel, plástico o cartón y protegido por una plancha de metacrilato transparente. Este material es un plástico transparente, barato y fácil de cortar para adaptarlo a las medidas de los carteles.

\subsection{Canales verticales, métodos de interpretación selectivos}

La variedad de personas que pueden visitar un museo es muy grande. Desde personas especializadas en la temática de las exposiciones hasta completos desconocedores de la misma, quienes van con un objetivo claro o quienes sólo esperan pasar un buen día de turismo, visitantes individuales, familias, personas mayores, grupos de escolares, etc. Cada uno de estos grupos presenta unas características diferentes y su acercamiento al patrimonio necesita de una mediación específica. Para llevar a cabo esa adaptación, los elementos fijos explicados en el apartado anterior presentas muchas limitaciones. Por ese motivo todo museo debe contar con personal especializado que sirva de intermediario entre el museo y el visitante: el departamento de acogida y el de difusión.

La atención al visitante en el momento de su llegada debería ser lo más personalizada posible. Cada individuo o grupo tiene unos intereses diferentes y el personal encargado de la recepción debe poder indicarles cuál es el recorrido más indicado para ellos. Esto es especialmente importante en museos 
grandes donde el número de salas y de posibles recorridos es amplio. Se puede también diseñar previamente varios itinerarios según las diferentes temáticas posibles. En el caso de la colonia, estas rutas pueden centrarse en los edificios de tipo industrial, los espacios domésticos o incluso una ruta por los edificios exteriores al núcleo principal (estación de ferrocarriles, casa de los Giles, colina del Cuco, horno de cal, cenador, etc.).

Otro aspecto muy importante son las visitas guiadas (Fig. 8). Estas son realizadas por un guía que trabaja para el museo, aunque algunos permiten también las visitas organizadas por guías que vienen con los grupos. El guía es el encargado de dirigir el recorrido y aportar las explicaciones que permitan comprender el patrimonio observado. Para ello debe adecuar el discurso a las necesidades e intereses de cada grupo y responder a sus preguntas o dudas. Este tipo de visita resulta más interesante para la mayoría de los visitantes, pues no requiere la lectura de la información escrita en los carteles y, si el guía emplea adecuadamente los recursos de que dispone, permite mantener la atención durante más tiempo (Valdés, 1999, pp. 197-198). Este tipo de visitas es el modelo principal que proponemos para la musealización de la colonia. Con ello se permite el acceso del público a determinados espacios interiores que normalmente se encontrarán cerrados o, por ejemplo, mostrar el funcionamiento de la

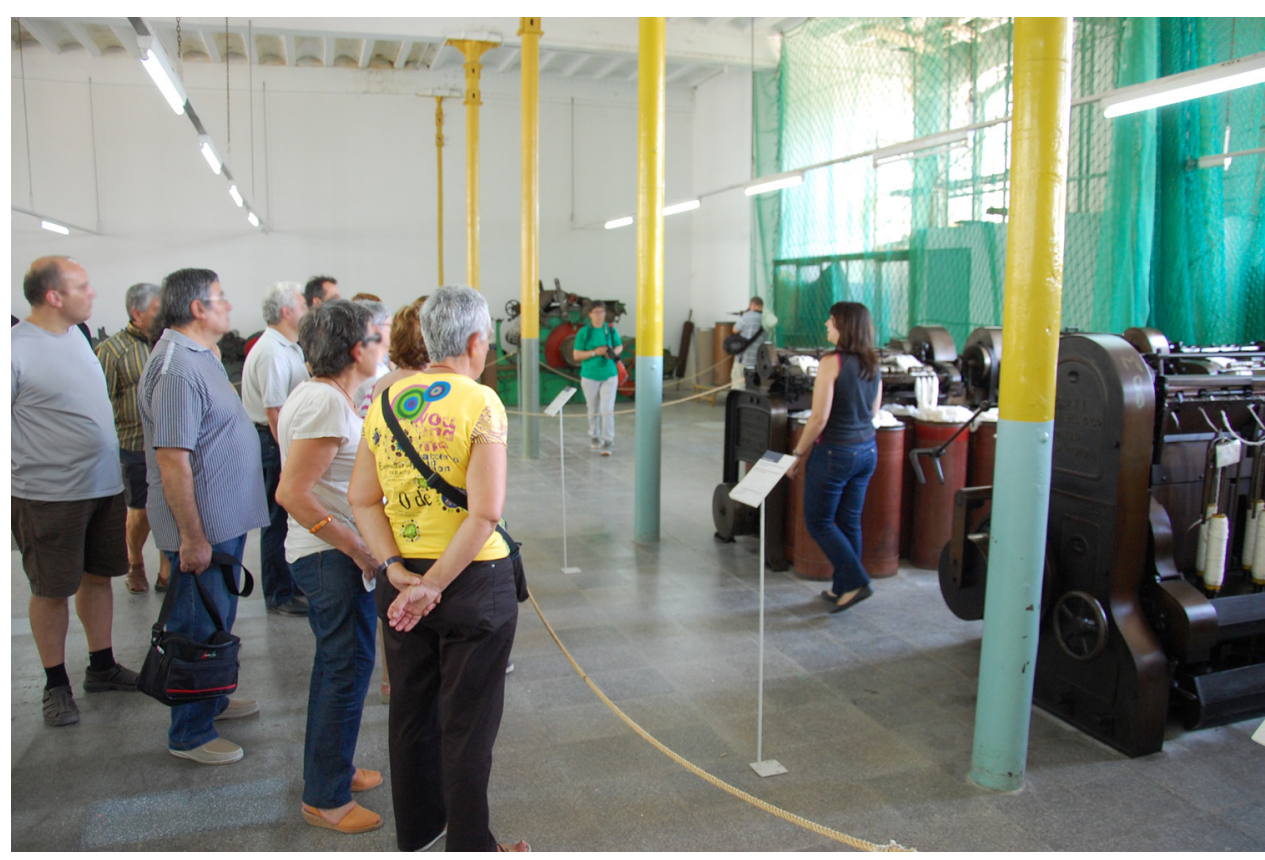

Fig. 8. Visita guiada mostrando el funcionamiento de una máquina textil en la colonia Cal Vidal (Barcelona) maquinaria de producción de vino o aceite.

Por último, el museo puede ofrecer una serie de actividades didácticas para grupos escolares durante las excursiones o familias con niños pequeños que visiten el museo fuera del horario lectivo. Conviene que este tipo de programas sean elaborados en colaboración con los centros educativos de la zona, con el fin de conocer las necesidades educativas de los alumnos y permitir a los profesores completar su visita con trabajo en el aula, antes o después de su paso por el museo. Además, estas actividades resultarán un complemento de la visita que permite a los niños conservar un recuerdo de su paso por el museo.

En el caso de las actividades didácticas destinadas a las familias, pueden organizarse de forma que duren una mañana o parte de la tarde. Al mismo tiempo, se debe ofrecer una actividad alternativa a los padres, bien dentro del mismo taller de sus hijos o en paralelo. De esta manera la posibilidad de la visita resulta mucho más interesante para ellos y contribuye a atraer público al museo.

\subsection{Canales radiales, la difusión de las actividades del museo}

Como toda institución pública o privada destinada a un público, las actividades y propuestas de un museo deben darse a conocer. El medio más común para ello es a través de la publicidad. Mediante anuncios en prensa escrita, carteles publicitarios en comercios o folletos informativos en 
las oficinas de turismo cercanas un museo puede dar a conocer sus actividades y atraer nuevos visitantes (Fig. 9). Este tipo de publicidad tiene la dificultad principal del precio relacionado con el alquiler de espacio en la prensa o los costes de la impresión. Todo ello sin que el museo pueda modificar su oferta o añadir nueva información de manera rápida. Sin embargo, a pesar de estas limitaciones, se trata de un recurso que ha de tenerse en cuenta, ya que muchos turistas o visitantes ocasionales pueden descubrir las actividades del museo a través de estos canales.

Por otro lado, gracias a las nuevas tecnologías y las redes sociales, los museos y otros espacios culturales tienen la posibilidad de enfocar su publicidad directamente hacia el usuario de una manera mucho más rápida y económica. Cualquiera que siga las actualizaciones de la página de Facebook o Twitter de un museo o que se haya inscrito a la lista de difusión de correo electrónico podrá estar fácilmente informado de las novedades y actividades a desarrollar. A través de estas herramientas, el personal del museo podrá publicar información relevante o compartir las novedades de la página web. También a través de dicha página o de un blog institucional los trabajadores del museo podrán compartir las actividades ya realizadas, anunciar las futuras, realizar artículos de divulgación y de opinión acerca múltiples aspectos

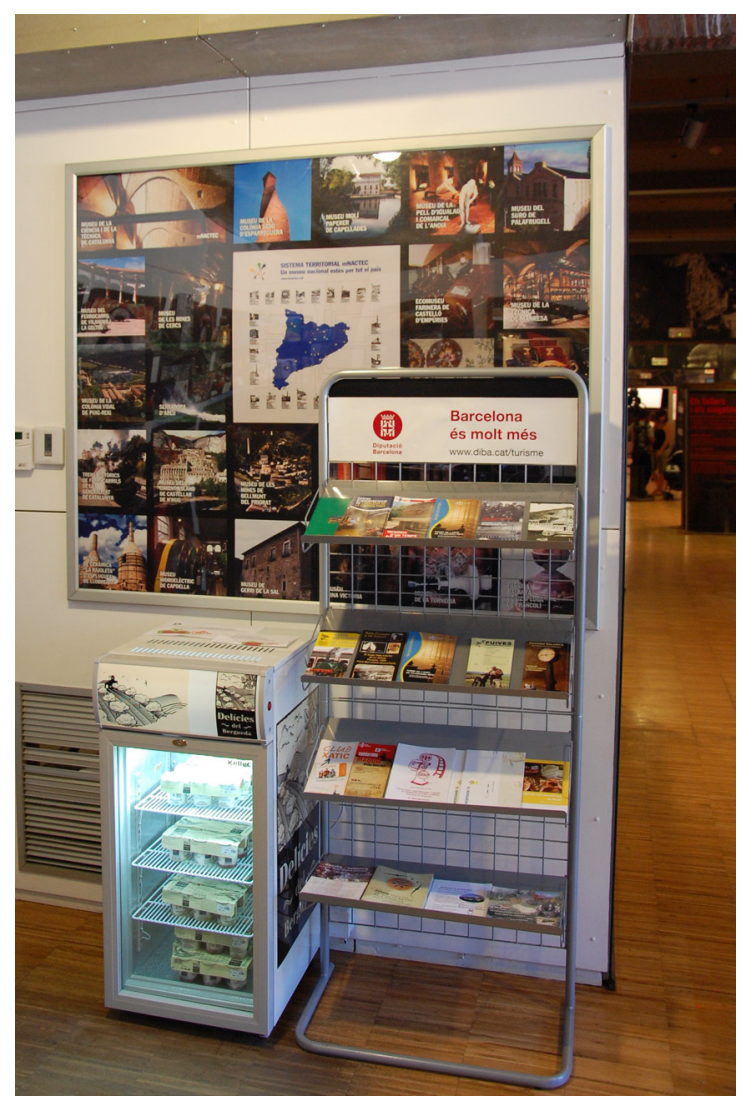

Fig. 9. Expositor con folletos informativos en el Museo de las Minas de Cercs (Barcelona) relacionados con la vida en el propio museo, etc. Es un medio mucho más rápido, directo y que permite interactuar con los visitantes. Además, los propios usuarios pueden contribuir a incrementar el alcance de esta publicidad al compartir en sus propios perfiles de redes sociales la información publicada por el museo.

Independientemente de cuales sean los medios de difusión empleados, la publicidad de las actividades debe estar acompañada de ciertas informaciones para que el público pueda preparar su visita. Es el caso de los horarios de apertura, la dirección del museo, los medios de transporte en común más cercanos y un plano que indique como llegar (especialmente en el caso de museos situados fuera de las ciudades), teléfonos de contacto, precios y tarifas especiales, etc. Toda la información ha de estar disponible y fácilmente accesible en la página web. Por ejemplo, mediante un enlace "Información práctica" o "Prepara tu visita" en la parte superior de la página principal. Incluso puede ser posible comprar los billetes de entrada o reservar actividades a través de esa misma vía. En cuanto a la información de los folletos o la prensa escrita, la falta de espacio puede obligar a indicar solamente los datos más importantes junto con la dirección de la página web para quien quiera ampliarlos.

\subsection{Canales lineales, información gestionada por el visitante}

Las mismas nuevas tecnologías que permiten una mejor difusión de las actividades de un museo pueden permitir a los usuarios realizar una visita más personalizada. Hoy en día, la mayor parte de la población dispone de un Smartphone con conexión a Internet. Esto hace posible que los museos pongan a disposición de los visitantes una mayor cantidad de información sin necesidad de 
instalar cientos de paneles. La herramienta más adecuada para ello son los códigos QR. Junto a la información básica que se propone a los visitantes en forma física se puedes añadir estas imágenes captables fácilmente mediante la cámara del portátil o la Tablet para, de esa manera, ser conducidos automáticamente a la información relacionada. Se permite así profundizar en ciertos aspectos de manera individual, mediante textos adicionales, galerías de imágenes, audios o videos, enlaces para descargar documentos, planos del museo, información sobre las visitas, etc. (Gómez, 2012, pp. 3-7). A ello puede añadirse la creación de una aplicación específica del museo o de alguna de sus exposiciones que sea descargable y ejecutable por el propio usuario de manera autónoma.

Para todo ello es necesario, lógicamente, disponer de conexión a Internet. Ya en el momento de realización del TFM la cobertura 3G en la colonia de Santa Eulalia era de una calidad suficiente para poder llevar a cabo una navegación rápida y fluida (De Arriba, 2012, pp. 103-104). Sin embargo, una solución adicional y cada vez más común en establecimientos culturales, es la instalación de una conexión Wifi abierta a la que los usuarios pueden conectarse libremente.

\section{SERVICIOS PARA LOS VISITANTES}

Todo museo es un espacio público donde miles o millones de personas visitarán cada año las exposiciones. Por ese motivo se han de asegurar unas condiciones adecuadas para la conservación de los bienes patrimoniales depositados, pero también una serie de servicios básicos necesarios para el visitante.

Antes, durante y al final de la visita, el usuario debe poder guiarse por el museo sin dificultades. El acceso al museo debe estar debidamente localizado, lo que en el caso de la colonia de Santa Eulalia esto supone nuevas señalizaciones en la autovía A-31 en las que se indique cuál es la salida que conduce al museo. Debe asegurarse también la disponibilidad de aparcamiento y la accesibilidad de todos los espacios, tanto de recepción como de exposición. Es recomendable también contar con un guardarropa o consignas y con un espacio de cafetería en el que los visitantes puedan descansar.

Durante el tránsito por el museo los itinerarios deben estar adecuadamente señalizados, con el fin de evitar la desorientación. Para ello se puede recurrir a señalización vertical, indicaciones en el suelo, planos, códigos de colores en las salas, etc. También es aconsejable que en los principales espacios del museo el visitante pueda localizar fácilmente a algún empleado al que pueda dirigirse en caso de necesidad.

Un museo ha de ser también un espacio agradable. Para ello se pueden definir algunas zonas de descanso, con bancos en los que el público pueda sentarse, y espacios de entretenimiento, especialmente para los niños. Resulta interesante en muchas exposiciones emplear algún audiovisual o animación que permita a los visitantes realizar una pausa sin perder el ritmo.

Finalmente, como todo espacio público, un museo debe contar con aseos accesibles para sillas de ruedas y cambiadores de bebés, botiquines, desfibriladores y elementos de seguridad antincendios como extintores, mangueras y un plan de evacuación.

\section{CONCLUSIONES}

Tal y como señalamos en el momento de escribir el Trabajo de Fin de Máster, la colonia de Santa Eulalia presenta un gran potencial como espacio museístico. Pocas fueron las colonias agrícolas que tuvieron un desarrollo tan grande en número de habitantes y variedad en su producción. Bien gestionado, este enclave podría dinamizar la oferta cultural del Vinalopó y la provincia de Alicante. 
Todo ello requeriría un gran trabajo de planificación, gestión y restauración. Sin embargo, esta sería una inversión que permitiría recuperar un entorno patrimonial de gran valor para explicar la evolución agrícola del siglo XIX y XX. La declaración del conjunto como Bien de Interés Cultural por parte de la Comunidad Valenciana refleja el fuerte interés por evitar que estos edificios se pierdan definitivamente. Sin embargo, todo lo que no sea una actuación rápida destinada a salvar los edificios de su destrucción conducirá a que dentro de unos años las noticias sean que los edificios han sido destruidos por la climatología.

A través del trabajo que sirve de base a este artículo buscábamos no sólo contribuir al conocimiento de la historia de la colonia, sino también mostrar cómo su recuperación es posible. El método escogido fue a través de darle una nueva utilidad cultural dentro de la economía de las comarcas donde se encuentra emplazada. Sin embargo, en última instancia este proyecto necesita de un impulso decidido por parte de los poderes locales y provinciales.

\section{BIBLIOGRAFÍA}

Abella, F. (1877). Manual de aguas, expropiación y colonias agrícolas. Madrid.

Belcher, M. (1997). Organización y diseño de exposiciones. Su relación con el museo. Gijón.

Canales, G. (1998). La colonización agraria en España y su incidencia en el poblamiento. En González Pérez, V. (coord), La Población Valenciana. Pasado, presente y futuro. Actas de las II Jornadas de Estudios sobre la Población Valenciana. Orihuela, 23 a 25 de septiembre de 1996, tomo I. Alicante, pp. 345-361.

De Arriba, H. (2012). La colonia de Santa Eulalia. Estudio y recuperación de un espacio agroindustrial del siglo XIX, (TFM Universidad de Alicante).

Espinosa, A. (2004). Los nuevos tipos de museo a comienzos del siglo XXI y la interpretación del patrimonio cultural (II). Boletín de Interpretación, no 10 , pp. 7-10.

Espinosa, A. y Bonmatí, C. (2012). La accesibilidad al patrimonio cultural, Material de apoyo de la asignatura Patrimonio y Gestión de proyectos Culturales del Máster Universitario Arqueología Profesional y Gestión Integral del Patrimonio de la Universidad de Alicante.

Gómez, MáS. (2012), QR codes en museos. Mediamusea.com. <http://mediamusea.files. wordpress.com/2010/10/qr-code-en-museos. pdf> (Consulta: 13-06-2016).
Hervás, R. et al. (2006). Guía de planificación estratégica. Materiales para el diseño $e$ implantación de un sistema de gestión de calidad en centros educativos, Generalitat Valenciana. < h t t p : / / w w w . c e i c e.g v a. e s / documents/162784507/162787169/guia_planif. pdf/b29592da-e86b-42d4-b00c-a06b41d74314> (Consulta 13-06-2016).

Hooper-Greenhill, E. (1998). Los museos y sus visitantes. Gijón.

Jaen, J. et al. (2000). La Colonia de Santa Eulalia. En Gil Peláez, F. J. (coord.), Historia de Sax, Tomo III. Sax, pp. 411-495.

Oyón, J.L. (1985). Colonias agrícolas y poblados de colonización. Arquitectura y vivienda rural en España (1850-1965) [Tesis doctoral], Universidad Politécnica de Barcelona.

Paniagua M.A. (1990). Colonias agrarias en la segunda mitad del siglo XIX en España. Actas Congreso de jóvenes historiadores y geógrafos, Tomo II. Madrid, pp. 823-833.

Valdés, Ma C. (1999). La difusión cultural en el museo: servicios destinados al gran público. Gijón.

Vázquez, V. (2008). Un delirio del Antiguo Régimen. La Colonia de Santa Eulalia, En Ponce, G. (coord.), Sax en la segunda mitad del siglo XIX. La modernización de una sociedad rural. Sax, pp. 31-34. 
Vázquez, V. (2010). La Colonia de Santa Eulalia, una joya por descubrir. Ecoeco, no 0, pp. 34-37.

"Ley de 21 de noviembre de 1855 sobre el establecimiento de colonias agrícolas" Gaceta de Madrid, número 1053, 22 de noviembre de 1855.

"Ley de 11 de julio de 1866 sobre el fomento de la población rural". Gaceta de Madrid, año CCV, número 195, 14 de julio de 1866.

"Ley de 3 de junio de 1868 sobre colonias agrícolas". Gaceta de Madrid, año CCVII, número 161, 9 de junio de 1868.
"Reglamento de la Ley de 11 de julio de 1866 sobre el fomento de la población rural". Gaceta de Madrid, año CCVI, número 240, 28 de agosto de 1866.

“Real Decreto 620/1987, de 10 de abril, del Reglamento de Museos de Titularidad Estatal y del Sistema de Museos". Boletín Oficial del Estado (BOE), número 114, 13 de mayo de 1987. 